\title{
Common Sense As Corporate Culture
}

\author{
John E. Simms, Ph.D., University of St. Thomas, USA \\ Hung Chan, Ph.D., San Diego State University, USA \\ Jim Hsieh, C.P.A., Network Funding, L.P., USA
}

\begin{abstract}
A discussion of the problems associated with the implementation of FAS 157 and inherent risk for small- to-medium sized firms in the mortgage industry. Emphasis is placed on components of corporate culture and an example is provided using Network Funding, L.P., a Houston-based mortgage banking firm.
\end{abstract}

Keywords: Subprime Mortgage; Corporate Culture; FAS-157

\section{INTRODUCTION}

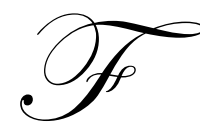

AS 157 allowed the implementation of mark-to-market accounting, and the role of mark-to-market accounting in the current financial crisis is still under debate. Mark-to-market accounting allowed many firms to mark up the value of certain assets and then use those assets as collateral for loans. There are only two certainties concerning the market: it will go up and it will go down. When the market goes down, the loans become under-collateralized and possibly callable. In a worst-case scenario, the total assets of the firm become less than the debt and the firm may face conditions of financial distress or even bankruptcy. Support for FAS 157 was hardly unanimous, with many practitioners, regulators and academics concerned that it violated the principles of historical cost and conservatism. There are many conditions under which historical cost can be bypassed (if reliability is not significantly impaired). On the other hand, the principle of conservatism is a primary functional directive to the responsibility of protecting the investors and the public from methodologies that may overstate assets or net income. Accountants and auditors working in the mortgage industry during the last six to eight years saw many examples of these types of assets or their derivatives.

The last several years have been a tumultuous time for the residential mortgage industry - to put it mildly. There have been changes in the market that resulted in foreclosure rates that can only be compared to the great depression. But even the 1930s pale in comparison to the sheer volume and dollar value of mortgage-based securities created and exchanged in today's market. One only needs to read the financial section of any major newspaper to see the litany of words used to describe the situation: disaster, meltdown, economic collapse. The common perception seems to be that it's going to get worse before it gets better. The analysis of the causes and effects from a macro perspective will be ongoing for years, perhaps decades.

Although most of the press coverage is about the failures, a great deal can be learned from the survivors. What did they do right? How did they maintain the self-discipline required not to buy into the hype of the subprime feeding frenzy? What internal controls were in place that prevented the firms from falling into substandard lending practices that increased risk beyond what in earlier times would have been considered unacceptable? Usually, it is the task of the controller to assess the risk exposure to the firm, while the treasurer negotiates debt covenants. The maintenance of internal controls concerning risk exposure and risk appetite are off essential importance to the accountant working in the industry, as well as external auditors in an engagement.

When an auditor conducts an initial walkthrough of a client, one of the primary factors under consideration is the culture. A firm's corporate culture is created from the top down, so interviews with top management are essential in the initial estimation of inherent risk. The auditor does not want to hear phrases like "Our sales people get the money - we settle the paperwork later." Granted, such a case would be extreme but certainly not unprecedented. Corporate culture is created by the extension, implementation and enforcement of the personal values and standards held by top management. 
The assessment of inherent risk requires that the auditor use interviews and other methods to determine whether the internal control system is in place and working. In small, privately held firms, internal control systems may not be as elaborate or formalized as those in larger, publicly owned firms. This does not lessen the importance of the internal control system - there are more instances of fraud in small-to-medium sized firms than in their larger counterparts. Smaller firms are often able to maintain a competitive advantage through a more streamlined organizational structure. The problems generated by such streamlining may include the lack of a separation of duties, failure to maintain the required paperwork, and/or the ability to bypass controls. At the level of corporate culture, a long-term orientation towards adding value rather than making money that is communicated, demonstrated and enforced at all levels can contribute significantly to an effective control environment.

\section{NETWORK FUNDING}

One of the survivors of the real estate "meltdown" is Network Funding, L.P., a mortgage bank based in Houston, Texas. Network Funding was founded as a wholesale mortgage company in 1998. In 2000, they began offering branch opportunities to qualified mortgage originators, creating an organizational structure that they believed would combine the traditional retail origination branch format with the best of the broker industry. The evidence indicates they were right: by 2003 Network Funding was originating over $\$ 500,000,000$ per year in single family mortgage loans, and it currently employs over 600 originators in nearly all 50 states.

The CEO, Rex Chamberlain, is a down-to-earth, middle-aged Texan with a slow drawl who gives the impression of thinking carefully before he speaks, which he does. He has served as CEO since co-founding Network Funding with the President, Gregory (Buzz) Baker. Buzz speaks with a more upbeat, lively conversational style, but he speaks with the authority of hard-won experience. The two share over 50 years of experience in the wholesale and retail mortgage banking business. The Chief Operations Officer, J. Thomas Orr, joined the firm in 2004 and brought a long history of success of his own (he is a past director of the Texas Mortgage Bankers Association and past President of the Houston Mortgage Bankers Association). This combined experience has allowed them to take a long term perspective in the midst of the upheavals of the last few years. So what kinds of values and standards do these people bring to their firm?

\section{Common sense}

"You can't get away from it. You can't let yourself get carried away by things that other people are saying," says Rex. "You have your criteria and you just have to stick to it." That isn't always easy to do. There was immense pressure to compromise from all directions - the applicants, real estate agents, independent brokers, and the banks. Sometimes the numbers simply don't support the request and you have to hold to the criteria in spite of pressure from the marketplace. "We had people sending us things that just didn't look any good, and we'd just say no. I'd have an application that said the guy was making $\$ 10,000$ a month and he wanted to buy an $\$ 800,000$ house. It's just not happening."

\section{Stick to proven strategies}

When the market began to be fueled by speculation, many market participants bought subprime loans at a price based on the belief that the loans could be resold, rather than paying the underlying risk-adjusted value. In other words, it was fine if the loans went bad as long as they weren't holding them when it happened. This resulted in a financial game of russian roulette where each player got paid for the click of an empty chamber. Rex didn't buy into it. He talks about the market of 2005 and protests the accusation of being conservative. "We're doing the same thing that we were doing ten years ago - the same thing everyone was doing then." Just because the market began applying a more "liberal" definition to credit worthiness, that didn't mean that Network Funding had to.

Like almost every firm in the marketplace, they were inundated with subprime opportunities. When subprime loans came their way, they did not finance them, but instead simply pointed them to other firms that were interested in financing at that risk level. They chose to accept a small commission instead of holding the loans themselves. It meant sacrificing sometimes significant short term profit opportunities, but doing business that way didn't fit in with the way they saw themselves and their company. It's important to note that they know very well 
where they "live" in the market. Rex points out that "We're not selling anything different than anyone else is: 30 year and 15-year fixed, some variable and ARMs." Buzz concurs: "It's all about service and it has been for a long time. Some places will take two weeks to get an answer. We'll have answer in a day, two at most. The real estate agents appreciate that."

\section{Communicate and enforce ethical standards}

They explain very simply that every employee knows the standards expected because they tell them. "Over the years, there have been a couple of people who crossed the line and we just had to let them go." Any deviation from the set criteria requires specific approval from management. Sometimes they invite independent brokers to join them. They look for people who do good, solid work - no short cuts. The better work they do, the better service the company can provide, leading to sustainable growth.

When asked about the fraud scandals among the leading national firms, Rex is quick to point out that the initial fraud is often committed by the borrowers. "People quit checking. They would just take it at face value." They are called stated income loans - some refer to them as "Liar's Loans." They find that kind of behavior morally offensive. There is also the case where a borrower is able to finance $80 \%$ of the home value and then turn around and finance the remaining $20 \%$ with a loan from the federal government, for example. They are adamant about this, pointing out that $80 \%$ of first-year foreclosures are people who took out federal deposit assistance loans. "They don't have any skin in the game. They realize they can't make the payments and they just walk away because they don't have anything invested in the house."

They believe that doing business that way is a losing game. The logic is inescapable: if the loan is defaulted, then the company loses money. Fifty years ago, a banker named O. B. Buck asked "What interest rate do we charge someone who's not going to pay us back?" The higher the risk, the greater interest must be charged to warrant making the loan, but at what point does a higher interest rate guarantee default? This is the area where the borrower has to do their own budgeting. Unrealistic or even fraudulent forecasts only make default inevitable. It doesn't help that various operators were more than willing to encourage it or at least turn a blind eye in order to get the dollar today, sacrificing their own principles and the promise of future business.

\section{Live your philosophy}

It's not just about business, it's about philosophy. In referring to press coverage on real estate moguls in trouble, Rex says "You hear these guys talking about their success in terms of how many people they put into houses. This idea that everyone deserves a house is an idea to which I don't agree. A house is a huge commitment, a huge responsibility, and not everybody has the means to do it." Network Funding looks for customers as willing partners, understanding that both sides succeed or fail together.

When asked what philosophy he brings to the firm, Buzz is quick to reply "I just keep my hands on the plow and my eyes on God." This phrase may seem simplistic, but it is profound and sends a powerful message to everyone in the value chain: Work hard and do what's right. It's a call to action, always staying within the constraints of acceptable moral, social and professional behavior. Part of this philosophy is the acceptance of the fact that the world, the nation, the market and even the firm itself is not always going to perform according to their hopes or expectations. Things out of their control are not the focus of their efforts. Whatever conditions are, the goal is honestly doing their best to provide value in some form for all the stakeholders, and they expect the same from their employees. This provides a foundation of trust within the workplace, evidenced by an atmosphere of eager yet relaxed enthusiasm in the office spaces. One employee brought her toddler who played among the chairs. No one thought twice about it - it's a friendly place where you don't have to worry what kind of language a young one may overhear.

\section{CONCLUSION}

It would be easy to point out that the last three points (stick to proven strategies, communicate and enforce ethical standards, and live your philosophy) are standard textbook fare. If that's true, then why did so many firms 
and individuals fall to the temptation of the subprime insanity? In many companies, policies are created, convincing memos are sent out, posters with catchy phrases are pinned to walls, and websites are developed with elaborate strategies for dealing with ethical dilemmas. The truth is that generally people do what they are paid for and try to do what is expected of them. When it is unclear what kind of behavior is allowed, people will do what they need to do in order to keep their job, make money, and be able to sleep at night. A clear message must be communicated, enforced and demonstrated.

Using proven strategies not only makes good business sense, but also provides a sense of stability. People who work in that kind of atmosphere value the security and continuity of consistent performance expectations. Communicating and enforcing ethical standards provides constraints on behavior which reduce the likelihood of external legal threats such as malpractice, negligence and so forth. It may also result in minimizing or even eliminating a multitude of internal threats to the firm such as discrimination and harassment. Clear standards of behavior also reduce stress in the workplace and thus increase productivity. When top management lives their philosophy (and it's difficult not to), it sends a message to everyone concerned - this is how it's done. Common sense is not uncommon - it's just rarely commented upon. When strong logic and equally strong principles are put into practice together, the result is leadership that provides good business, done by good people, doing good work.

As a final note, when asked what the greatest threats to Network Funding were, Buzz answered "The banks don't want to lend money. A few years ago, they were pushing all kinds of things at us that we just weren't going to do. Now, I have some of the best paper I've seen in ten years on my desk and the banks don't want to lend any money. It's ironic."

\section{AUTHOR INFORMATION}

John E. Simms, Ph.D. (corresponding author), is an Assistant Professor at the University of St. Thomas in Houston Texas specializing in managerial and cost accounting. E-mail: simmsj@stthom.edu. Corresponding author.

Hung Chan, PhD., is an Assistant Professor at San Diego State University specializing in accounting information systems and corporate governance.

Jim Hsieh, C.P.A., is Controller for Network Funding, L.P., in Houston Texas. 